\title{
Survei Aksesibilitas Fisik dan Sosial sebagai Dasar Penyusunan Grand Design Desa Inklusif
}

\author{
Astri Hanjarwati ${ }^{*}$, Jamil Suprihatiningrum ${ }^{2}$, Siti Aminah ${ }^{3}$ \\ UIN Sunan Kalijaga Yogyakarta, Jl. Laksda Adisucipto, Yogyakarta, Indonesia \\ *Corresponding Author Email: astrio20585@gmail.com
}

Received: o1 April 2019; Revised: 21 April 2020; Accepted: 14 January 2021

\begin{abstract}
Abstrak: Desa Trimurti memiliki jumlah penyandang disabilitas tertinggi di Kabupaten Bantul. Hal ini menjadikan Desa Trimurti berpotensi untuk menjadi desa inklusif. Penelitian ini bertujuan untuk mengetahui aksesibilitas fisik dan sosial penyandang disabilitas. Metode penelitian yang digunakan adalah penelitian survei, dengan sampel 6o penyandang disabilitas (30\% dari total jumlah penyandang disabilitas). Analisis data secara deskriptif menggunakan spss versi 23. Hasilnya survei menunjukkan: (1) aksesibilitas sosial di Desa Trimurti sangat baik ditunjukkan dengan sikap terhadap penyandang disabilitas yang baik; ketersediaan layanan pendidikan, kesehatan dan informasi sangat baik. (2) aksesibilitas fisik menunjukkan bahwa sebagian besar bangunan fisik tidak dapat diakses, kecuali Sekolah Khusus (SLB) dan Puskesmas Srandakan. (3) aksesibilitas finansial, kebijakan dan pengetahuan para penyandang cacat masih sangat terbatas; penyandang disabilitas tidak memiliki akses ke modal dan peluang kerja. Berdasarkan pada hasil survei tersebut dapat disusun kebijakan yang inklusif sehingga terwujud desa inklusif yang ramah terhadap penyandang disabilitas
\end{abstract}

Kata Kunci: Aksesibilitas fisik, Aksesibilitas sosial, Grand design, Desa Inklusif, Penyandang disabilitas

\section{Survey of Physical and Social Accessibility as a Base Preparation of the Inclusive Village Grand Design}

\begin{abstract}
Trimurti Village has the highest number of persons with disabilities in Bantul Regency. This makes Trimurti Village has the potential to become an inclusive village. This study aims to determine the physical and social accessibility of persons with disabilities. The research method used was survey research, with a sample of 60 people with disabilities (30\% of the total number of people with disabilities). Descriptive data analysis using SPSS version 23. The survey results show: (1) social accessibility in the village of Trimurti is very well demonstrated by a good attitude towards persons with disabilities; the availability of education, health and information services is very good. (2) physical accessibility shows that most of the physical buildings are inaccessible, except for Special Schools (SLB) and the Heatlh Center (Puskesmas) Srandakan. (3) financial accessibility, policy and knowledge of people with disabilities is still very limited; people with disabilities do not have access to capital and employment opportunities. Based on the results of the survey, inclusive policies can be developed so that an inclusive village that is friendly to people with disabilities can be developed.
\end{abstract}

Keywords: People with disabilities, Physical accessibility, Social accessibility, Grand design, Inclusive Village

How to Cite: Hanjarwati, A, Suprihatiningrum, J, Aminah, S (2021). Survei Aksesibilitas Fisik dan Sosial sebagai Dasar Penyusunan Grand Design Desa Inklusif. JPPM (Jurnal Pendidikan dan Pemberdayaan Masyarakat), 8(1), 1 - 17. Doi: https://doi.org/10.21831/jppm.v8i1.24266 


\section{JPPM (Jurnal Pendidikan dan Pemberdayaan Masyarakat), 8 (1), 2021 - 2}

Astri Hanjarwati, Jamil Suprihatiningrum, Siti Aminah

\section{PENDAHULUAN}

Pembangunan masyarakat tidak lepas dari dua hal utama, yaitu pembangunan infrastruktur dan pembangunan mental masyarakat itu sendiri (Australian Government, 2008; CABE. 2008; Colantonio \& Dixon, 2009; Donahue, S. \& Gheerawo, R., 2007). Pembangunan yang baik menurut UU Desa No. 6 Tahun 2014 adalah pembangunan yang melibatkan seluruh komponen masyarakat termasuk penyandang disabilitas sehingga hasil pembangunan dapat dimanfaatkan bersama. UU ini tidak secara eksplisit menyebutkan bahwa penyandang disabilitas menjadi prioritas baik sebagai subjek maupun objek pembangunan, meskipun selama ini mereka menjadi bagian integral dari desa.

Menurut pendapat Yulianto bahwa masyarakat penyandang disabilitas sebenarnya bukan hanya penerima manfaat langsung dari pelaksanaan UU Desa, namun juga bagian dari sumber daya manusia yang ada di desa (Yulianto, 2015) yang harus dimanfaatkan. Berdasarkan penelitian yang dilakukan oleh LSM Ciqal pada tahun 2016 menunjukkan bahwa sebagian besar desa belum menaruh perhatian pada penyandang disabilitas khususnya dalam perencanaan dan penganggaran desa (Ciqal, 2016). Hal tersebut disebabkan oleh minimnya data penyandang disabilitas yang dimiliki desa dan masih minimnya perspektif mengenai penyandang disabilitas di pemerintah desa, dimana menurut Heinicke-Motsch \& Sygall (2003) penyandang disabilitas seharusnya diberi akses untuk berpartisipasi dalam pembangunan.

Beberapa desa di Kabupaten Gunung Kidul sudah memberikan ruang partisipasi bagi penyandang disabilitas untuk terlibat dalam proses tersebut, namun hal tersebut tidak diimbangi dengan penyediaan infrastruktur fasilitas publik yang mudah diakses oleh penyandang disabilitas (wawancara dengan warga penyandang disabilitas di Kabupaten Gunung kidul, April, 2016). Minimnya partisipasi juga disebabkan oleh faktor psikologis individu penyandang disabilitas itu sendiri, mulai sikap minder, tidak percaya diri, dan tingkat pendidikan yang rendah (Ciqal, 2016).

Berdasarkan hasil penelitian yang di lakukan LSM Ciqal di 4 Desa di Yogyakarta dan NTT, menunjukkan bahwa keterbatasan anggaran dan kewenangan selama ini sering dijadikan alasan pemerintah desa untuk tidak melibatkan seluruh kelompok masyarakat dalam proses perencanaan pembangunan (Ciqal, 2016). Sejak UU Desa disahkan, hal ini tidak bisa lagi digunakan sebagai alasan untuk eksklusif dan tidak transparan. Dana 1,4 Milyar yang diberikan secara bertahap dari pusat ke desa tersebut dapat dimanfaatkan untuk kesejahteraan seluruh masyarakat di desa. Amanat tersebut tercantum dalam pasal 3 UU Desa tentang Pengaturan Desa, hendaknya berasaskan rekognisi, subsidiaritas, keberagaman, kebersamaan, kegotongroyongan, kekeluargaan, musyawarah, demokrasi, kemandirian, partisipasi, kesetaraan, pemberdayaan dan keberlanjutan. Artinya bahwa partisipasi dan kesetaraan dalam pengaturan desa harus inklusif (Council, 2009). Perencanaan, pelaksanaan, pengawasan, pertanggungjawaban menjadi ruang strategis bagi penyandang disabilitas untuk ikut terlibat.

Keterlibatan penyandang disabilitas dalam proses pembangunan diharapkan dapat mewujudkan apa yang disebut dengan desa inklusif. Terkait dengan desa inklusif, penyandang disabilitas menjadi salah satu poin penting dalam proses mewujudkan desa inklusif ini. Secara regulasi, sejak diratifikasinya Convention on the Rights of People with Disabilities (CRPD) pada Oktober 2011 menujukkan bahwa Indonesia mulai menaruh perhatian kepada penyandang disabilitas dan seluruh aspek yang berkenaan dengannya. CRPD ini kemudian diterjemahkan ke dalam beberapa perundangan baik tingkat nasional maupun regional. Misalnya saja, UndangUndang No. 8 Tahun 2016 mengenai Penyandang Disabilitas yang baru disahkan dapat dianggap sebagai mandat bagi seluruh pemangku kebijakan di semua level termasuk desa untuk mempertimbangkan dan mengikutsertakan penyandang disabilitas dalam kerangka dan proses pembangunan daerah.

Salah satu wujud nyata dari adanya mandat UU ini adalah dideklarasikannya Provinsi Daerah Istimewa Yogyakarta (DIY) sebagai Provinsi Inklusif pada tahun 2014 (Maftuhin, dkk., 


\section{JPPM (Jurnal Pendidikan dan Pemberdayaan Masyarakat), 8 (1), 2021 - 3}

Astri Hanjarwati, Jamil Suprihatiningrum, Siti Aminah

2016) bahkan jauh sebelum UU tentang Penyandang Disabilitas disahkan. Deklarasi ini tentunya diiringi dengan berbagai kebijakan dan implementasinya baik pada tingkat provinsi, kabupaten, kecamatan hingga desa/kelurahan. Salah satunya adalah upaya beberapa desa untuk mewujudkan dirinya menjadi desa inklusif.

Melihat permasalahan mengenai minimnya peran serta kaum penyandang disabilitas dalam proses pembangunan desa, Sasana Integrasi dan Advokasi Difabel (SIGAB) melaksanakan program Rintisan Desa Inklusi (RINDI) dengan menggandeng Combine Resource Institution (CRI) yang didukung oleh The Asia Foundation (Yulianto, 2015). Program ini mulai dirintis sejak tahun 2015 di delapan desa yaitu Kabupaten Sleman dan Kulon Progo. Dua desa yaitu Desa Sendangtirto, Kecamatan Berbah dan Desa Sendangadi, Kecamatan Mlati di Sleman dan enam desa di Kabupaten Kulon Progo, yakni Desa Sidorejo, Desa Gulurejo, Desa Ngentakrejo, desa Wahyuarjo, Desa Jatirejo, dan Desa Bumirejo yang semuanya di Kecamatan Lendah dilibatkan dalam proyek ini (Sigab, 2016).

Sayangnya, program Rintisan Desa Inklusif baru mencakup di dua Kabupaten yaitu Sleman dan Kulon Progo padahal Kabupaten Bantul mempunyai jumlah populasi penyandang disabilitas yang secara statistik lebih banyak setelah terjadi gempa bumi tahun 2006 dibanding kabupaten lainnya. Jumlah difabel daksa keseluruhan di Kabupaten Bantul berjumlah 5.900 orang yang terdiri dari dewasa dan anak-anak yang tersebar di 17 Kecamatan. seperti tertera di Tabel 1.

Tabel 1. Jumlah Penyandang Disabilitas Daksa di Kabupaten Bantul Tahun 2015

\begin{tabular}{llc}
\hline No & \multicolumn{1}{c}{ Kecamatan } & Jumlah \\
\hline 1. & Bambanglipuro & 402 \\
2. & Banguntapan & 298 \\
3. & Bantul & 372 \\
4. & Dlingo & 268 \\
5. & Imogiri & 407 \\
6. & Jetis & 380 \\
7. & Kasihan & 403 \\
8. & Kretek & 419 \\
9. & Pajangan & 175 \\
10 & Pandak & 430 \\
11 & Piyungan & 273 \\
12 & Pleret & 303 \\
13 & Pundong & 296 \\
14 & Sanden & 286 \\
15 & Sedayu & 203 \\
16 & Sewon & 419 \\
17 & Srandakan & 430 \\
\hline
\end{tabular}

Sumber: Data Dinas Sosial Kabupaten Bantul Tahun 2016

Desa Trimurti, Kecamatan Srandakan, memiliki jumlah penyandang disabilitas terbanyak yaitu 224 orang. Jumlah tersebut terbagi ke dalam tujuh jenis disabilitas yaitu daksa (65 orang), ganda (9 orang), mental (75 orang), netra (21 orang), rungu wicara (18 orang), eks kronis (12 orang), dan eks psikotik ( 24 orang). Jumlah penyandang disabilitas yang besar ini merupakan potensi sumber daya yang baik dan sepatutnya dilibatkan dalam proses pembangunan desa sehingga ruang partisipasi seluruh masyarakat dapat terwujudkan, dengan kata lain akan tercipta desa yang "inklusif”.

Dengan mengadaptasi beberapa konsep desa inklusi yang menggunakan prinsip Universal Design for Sustainability Development (Salisbury District Council Core Strategy Consultation. 2007; West, Badham, 2008; Western Australian Planning Commission, Oct 2007; Wood, Shannon, Bulsara, Pikora, McCormack, \& Giles-Corti, 2008; Woodcraft, Hackett \& CaistorArendar, 2011), kegiatan Pengabdian kepada Masyarakat (PkM) ini akan memfokuskan pada upaya advokasi kepada kepala desa dan perangkat serta stakeholders terkait untuk membuat 


\section{JPPM (Jurnal Pendidikan dan Pemberdayaan Masyarakat), 8 (1), 2021 - 4}

Astri Hanjarwati, Jamil Suprihatiningrum, Siti Aminah

dan mengembangkan grand design desa inklusif, sehingga seluruh kepentingan masyarakat (termasuk kelompok penyandang disabilitas) dapat terpenuhi secara proporsional dan adil.

Desa inklusif dapat terwujud jika ditopang oleh dua hal, yaitu 1) persepsi dan prinsip inklusif yang sudah membudaya (Ferrie, D., 2008; Hayes, Gray, \& Edwards, 2008; HeinickeMotsch \& Sygall, 2003) dan 2) infrastruktur bangunan yang didesain sedemikian rupa sehingga aksesibel bagi penggunanya (Elina \& Ann 2012). Jika dua hal ini dapat terpenuhi, maka sustainibility dari desa tersebut dapat terjaga, berkembang, bahkan mampu mewujudkan apa yang disebut dengan masyarakat madani (Malloy, 2015; Palich, \& Edmonds, 2013).

Pada poin pertama, membudayakan persepsi dan prinsip inklusif tidaklah mudah dan tentu membutuhkan waktu. Hal ini terkait dengan pengetahuan masyarakat mengenai arti inklusif dan disabilitas. Budaya yang ada saat ini (hasil wawancara pada penduduk Desa Trimurti Srandakan Bantul) mengenai penyandang disabilitas masih sebatas pada kelemahan dan kekurangan penyandang disabilitas itu sendiri, belum melihat pada potensi dan kelebihan yang dimilikinya. Budaya dan persepsi seperti ini dikenal sebagai traditional medical model (Barnes \& Mercer, 2004; Ferguson and Nusbaum, 2012) dalam studi mengenai disabilitas. Model ini melihat penyandang disabilitas sebagai sebuah isu individual dimana ketika mengambil kebijakan selalu meletakkan penyelesaian masalah dari kacamata medis atau dapat dikatakan bersifat rehabilitatif, tanpa mempertimbangkan isu-isu sosial yang melingkupinya. Pandangan ortodok dari penggagas model ini tentunya mendapat reaksi dari tokoh-tokoh sosialis.

Oleh karena itu, muncullah pendekatan baru yang dikenal dengan social model, yang pada tahun 1976 untuk pertama kalinya dipublikasikan oleh The Fundamental Principles of Disability by the Union of the Physically Impaired Against Segregation (UPIAS) (Barnes \& Mercer, 2004). Model sosial lebih menekankan pada interaksi sosial antara penyandang disabilitas dan lingkungannya. Model sosial menurut Barnes \& Mercer (2004), menekankan pada struktur sosial yang tidak memihak pada penyandang disabilitas. Misalnya saja, potensi yang dimiliki oleh penyandang disabilitas tidak dapat muncul atau bahkan berkembang karena adanya hambatan mobilitas yang disebabkan tidak aksesibelnya tempat-tempat dan fasilitas umum. Oleh karena itu, adaptasi lingkungan (fisik dan sosial) menjadi concern dari model ini ketika digunakan untuk menyelesaikan masalah yang berkaitan dengan penyandang disabilitas. Kedua model tentang disabilitas tadi tentunya memiliki kelebihan dan kekurangan masing-masing. Hanya saja, masyakarat perlu diedukasi mengenai hal ini agar ketika proses pembangunan berjalan, kedua model ini dapat menjadi rujukan untuk dipilih mana yang terbaik untuk diadaptasi atau bahkan memungkinkan untuk diambil kelebihan dari kedua model tersebut agar tercipta kebijakan yang komprehensif dan adil.

Poin kedua yang penting diperhatikan adalah aksesibilitas bangunan fisik (Elina \& Ann 2012). The Department of Economic and Social Affairs (DESA) of the United Nations mencatat bahwa aksesibilitas adalah hak asasi setiap warga negara (Rapley, 2013). Dalam setiap pembangunan aksesibilitas hendaknya menjadi bagian tak terpisahkan dari desain dan pelaksanaannya. Rapley (2013) menambahkan bahwa memberikan aksesibilitas berarti sama dengan memberikan kebebasan setiap individu untuk hidup mandiri dan dapat berpartisipasi penuh dalam segala aspek kehidupan. Tidak hanya itu, bangunan fisik yang aksesibel juga memberikan kesempatan setiap orang untuk memiliki personal mobility dan kebebasan berekspresi, berpendapat, dan mengakses informasi (Rapley, 2013).

Bersama dengan mitra, kegiatan ini telah berhasil merumuskan indikator (baru) desa inklusif berdasarkan dua studi utama, yaitu studi yang dilakukan oleh Maftuhin, dkk. (2016) dan 7 prinsip universal design yang telah berhasil diadopsi oleh berbagai negara.

Hasil studi Maftuhin, dkk. (2016):

1. Lingkungan fisik (bangunan dan infrastruktur) yang aksesibel Indikator:

a. Gedung pemerintah dan swasta, terutama dalam penyedia layanan publik;

b. Sarana dan prasarana; jalan, jembatan, halte, ATM; 
JPPM (Jurnal Pendidikan dan Pemberdayaan Masyarakat), 8 (1), 2021 - 5

Astri Hanjarwati, Jamil Suprihatiningrum, Siti Aminah

c. Kebijakan dan implementasi prinsip aksesibilitas harus sampai di tingkat kelurahan.

2. Lingkungan sosial yang positif

Indikator:

a. Masyarakat umum-termasuk anak-anak, penyedia layanan publik-pemerintah dan swasta, memahami disabilitas secara positif (penyebab, deteksi dini, bagaimana berinteraksi, bersosialisasi dan pengembangan potensi);

b. Tersedia beragam media informasi mengenai disabilitas bagi seluruh lapisan masyarakat-anak-anak, remaja, orang dewasa, tokoh masyarakat, guru, dan penyedia layanan publik-pemerintah dan swasta.

3. Keterjangkauan

Indikator:

a. Tersedia program pemerintah yang memberikan akses permodalan bagi penyandang disabilitas;

b. Tersedia program pemerintah yang memberikan perlindungan dalam mendapatkan akses permodalan dari swasta;

c. Tersedia perlindungan dari pemerintah agar penyandang disabilitas dapat mengakses jasa perbankan;

d. Tersedia koperasi atau sistem penyediaan modal yang didukung pemerintah untuk kesejahteraan penyandang disabilitas;

e. Tersedia dukungan pembiayaan yang memudahkan penyandang disabilitas mengakses sekolah, layanan kesehatan dan pekerjaan (misal, konsesi dan pemotongan biaya).

4. Ketersediaan

Indikator:

a. Pusat layanan kesehatan disediakan dekat dengan tempat tinggal penyandang disabilitas—atau didekatkan, home care dan home visit);

b. Pengembangan sekolah inklusi dilakukan agar dekat dengan siswa penyandang disabilitas;

c. Ketersediaan petugas layanan publik yang memahami dan memiliki kemampuan secara terlatih dalam memberikan layanan spesifik;

d. Petugas terapi dan konselor bagi orangtua dengan anak penyandang disabilitas, setidaknya sampai di level kecamatan.

5. Kualitas

Indikator:

a. Disabilitas menjadi perspektif semua program pembangunan;

b. Isu disabilitas dimasukkan dalam program-program penanggulangan kemiskinan dan lintas sektoral;

c. Penyandang disabilitas mendapat akses berpartisipasi dalam Musrenbang di semua level perencanaan;

d. Tersedianya indikator kota inklusi yang disusun dan dilihat sebagai capaian setiap tahun atau setiap tahapan untuk menjaga konsistensi.

6. Partisipasi

Indikator:

a. Keterlibatan dalam proses pengambilan kebijakan di semua tingkatan-Musrenbang;

b. Keterlibatan penyandang disabilitas dalam kegiatan kemasyarakatan;

c. Keterlibatan penyandang disabilitas dalam kegiatan remaja dan anak;

d. Keterlibatan penyandang disabilitas dalam Pemilukada, Pemilu DPR dan Presiden.

Prinsip Universal Design (The Center for Universal Design, 1997) beberapa indikator desa inklusif harus memenuhi kriteria berikut ini.

1. Equitable Use (Penggunaan yang Merata)

Desainnya berguna dan bisa dipasarkan untuk orang dengan kemampuan yang beragam.

Pedoman:

Copyright @ 2020, JPPM, ISSN 2355-1615 (print), ISSN 2477-2992 (online) 


\section{JPPM (Jurnal Pendidikan dan Pemberdayaan Masyarakat), 8 (1), 2021 - 6}

Astri Hanjarwati, Jamil Suprihatiningrum, Siti Aminah
a. Berikan sarana penggunaan yang sama untuk semua pengguna: identik bila memungkinkan; Setara bila tidak
b. Hindari memisahkan atau menstigmatisasi pengguna manapun.
c. Ketentuan untuk privasi, keamanan, dan keamanan harus sama tersedia bagi semua pengguna.
d. Buatlah desain menarik bagi semua pengguna.

2. Flexibility in Use (Penggunaan yang Fleksibel)

Desainnya mengakomodasi beragam pilihan dan kemampuan individu.

Pedoman:
a. Berikan pilihan metode penggunaan.
b. Mengakomodasi akses dan penggunaan kanan dan kiri.
c. Memfasilitasi akurasi dan ketepatan pengguna.
d. Sediakan kemampuan beradaptasi dengan kecepatan pengguna.

3. Simple and Intuitive Use (Sederhana dan Intuitif)

Penggunaan desain mudah dimengerti, terlepas dari pengalaman, pengetahuan, kemampuan berbahasa, atau tingkat konsentrasi pengguna.

Pedoman:

a. Hilangkan kompleksitas yang tidak perlu.

b. Konsisten dengan harapan dan intuisi pengguna.

c. Mengakomodasi berbagai kemampuan membaca dan bahasa.

d. Atur informasi sesuai dengan kepentingannya.

e. Memberikan dorongan dan umpan balik yang efektif selama dan setelah penyelesaian tugas.

4. Perceptible Information (Informasi yang jelas)

Desain mengkomunikasikan informasi yang diperlukan secara efektif kepada pengguna, terlepas dari kondisi sekitar atau kemampuan sensorik pengguna.

Pedoman:

a. Gunakan mode yang berbeda (bergambar, lisan, taktil) untuk pengulangan informasi penting.

b. Sediakan kontras yang memadai antara informasi penting dan sekitarnya.

c. Maksimalkan "keterbacaan" dari informasi penting.

d. Bedakan elemen dengan cara yang dapat dijelaskan (yaitu, memudahkan memberi petunjuk atau petunjuk arah).

e. Berikan kompatibilitas dengan berbagai teknik atau perangkat yang digunakan oleh orang-orang dengan keterbatasan sensorik.

5. Tolerance for Error (Toleransi akan kesalahan)

Desain meminimalkan bahaya dan konsekuensi buruk dari tindakan disengaja atau tidak disengaja.

Pedoman:

a. Susun elemen untuk meminimalkan bahaya dan kesalahan: elemen yang paling sering digunakan, paling mudah diakses; unsur-unsur berbahaya dihilangkan, diisolasi, atau terlindung.

b. Berikan peringatan bahaya dan kesalahan.

c. Berikan fitur yang tidak aman.

d. Mencegah tindakan tak sadar dalam tugas yang membutuhkan kewaspadaan.

6. Low Physical Effort (Meminimalkan usaha)

Desainnya bisa digunakan secara efisien dan nyaman dan dengan minimal kelelahan. Pedoman:

a. Izinkan pengguna untuk mempertahankan posisi tubuh netral.

b. Gunakan kekuatan operasi yang masuk akal.

c. Minimalkan tindakan berulang. 
JPPM (Jurnal Pendidikan dan Pemberdayaan Masyarakat), 8 (1), 2021 - 7

Astri Hanjarwati, Jamil Suprihatiningrum, Siti Aminah

d. Minimalkan usaha fisik yang berkelanjutan.

7. Size and Space for Approach and Use (Ukuran dan Ruang untuk Pendekatan dan Penggunaan)

Ukuran dan ruang yang sesuai disediakan untuk pendekatan, jangkauan, manipulasi, dan penggunaan terlepas dari ukuran, postur, atau mobilitas pengguna.

Pedoman:

a. Berikan garis pandang yang jelas ke elemen penting untuk pengguna yang duduk atau berdiri.

b. Buat jangkauan ke semua komponen yang nyaman untuk pengguna yang duduk atau berdiri.

c. Mengakomodasi variasi dalam ukuran tangan dan pegangan.

d. Sediakan ruang yang memadai untuk penggunaan alat bantu atau bantuan pribadi.

\section{METODE}

Metode penelitian yang digunakan untuk melakukan assessment terhadap penyandang disabilitas dan aksesibilitas fisik desa adalah kuantitatif survei. Untuk melihat aksesibiltas sosial digunakan instrumen hasil perumusan indikator desa dari penelitian Maftuhin, dkk. (2016) dan Universal Design, sedangkan untuk aksesisbiltas fisik menggunakan kuesioner hasil adopsi penelitian Ro'fah, Hanjarwati, Suprihatiningrum (2016) mengenai aksesibilitas bangunan fisik bagi penyandang disabilitas.

Indikator desa inklusif yang berhasil dirumuskan untuk penyusunan kuesioner aksesibiltas sosial adalah:

1. Lingkungan Sosial yang Positif;
a. Sikap
b. Persepsi
c. Pengetahuan

2. Keterjangkauan;
a. Keuangan yang Aksesibel
b. Investasi pemerintah dan swasta

3. Ketersediaan ;

4. Kualitas;
a. Pengarusutamaan
b. Lintas Sektor
c. Konsisten
d. Kolaboratif

5. Partisipasi;

a. Proses Politik

b. Kebijakan Politik

Indikator ini terdiri dari 72 butir pernyataan yang diformat dalam bentuk kuesioner semiterbuka.

Adapun, untuk survei lingkungan fisik, indikator yang digunakan adalah: ukuran dasar ruang, jalur pedestrian, parkir, pintu, ramp, tangga, lift, toilet. Wastafel, Rambu dan petunjuk brailer, Buku Ajar Format Alternatif, Alat Pembelajaran, Guru Pendamping Kelas (GPK), Meja Pendaftaran, Meja Periksa, Informasi dalam format Braille/Audio, Penerjemah Bahasa Isyarat, Ruang Tunggu, Kamar Pasien, Rambu dan Marka Jalan.

Bangunan fisik yang di survei adalah Kantor Desa Trimurti; Kantor Kecamatan Srandakan; Kantor KUA Srandakan; Polsek Srandakan; Puskesmas Srandakan; empat sekolah yaitu SLB,TK, SD, SMP, SMU; Jalan utama di Desa, dan tempat ibadah (salah satu masjid desa). Untuk survei aksesesibilitas sosial, sampel diambil dengan teknik proporsional random sampling. Proporsional random sampling ini dilakukan dengan mengambil 30\% dari masing-masing total jumlah berdasarkan jenis disabilitas. Distribusi sampel dapat dilihat pada Tabel 2. 
JPPM (Jurnal Pendidikan dan Pemberdayaan Masyarakat), 8 (1), 2021 - 8

Astri Hanjarwati, Jamil Suprihatiningrum, Siti Aminah

Tabel 2. Distribusi Sampel Asessment Penyandang Disabilitas Desa Trimurti

\begin{tabular}{llll}
\hline No & Jenis Disabilias & Jumlah Populasi & Jumlah sampel \\
\hline $\mathbf{1}$ & Daksa & 65 & $\mathbf{2 0}$ \\
$\mathbf{2}$ & Mental & 75 & 23 \\
3 & Netra & 21 & 7 \\
4 & Rungu wicara & 18 & 6 \\
5 & Ganda & 9 & 4 \\
& Jumlah & $\mathbf{1 8 8}$ & $\mathbf{6 o}$ \\
\hline
\end{tabular}

Sumber: olah data peneliti tahun 2018, berdasarkan data dinas sosial kab. Bantul tahun 2016.

Proses pengambilan data dengan wawancara terstruktur berdasarkan pada kuesioner dan melakukan chek list aksesibilitas fisik. Semua proses dilakukan oleh peneliti dan dibantu oleh penyurvei/asisten peneliti yang berasal dari Desa Trimurti. Pemilihan asisten peneliti ini bertujuan agar responden merasa tidak canggung dan mendapatkan data yang lengkap dan akurat. Sebelum melakukan pengambilan data, semua penyurvei/asisten peneliti dilatih terlebih dahulu untuk memahami kuesioner. Semua pertanyaan dalam kuesioner dibacakan oleh penyurvei/asisten peniliti kemudian responden menjawab pertanyaan.

Analisis data dilakukan dengan olah data statistik dengan menggunakan SPSS versi 23. Beberapa uji yang dilakukan diantaranya: uji validitas, reliabilitas, normalitas, dan deskripsi data. Uji deskripsi data dilakukan untuk mengetahui kondisi penyandang disabilitas berdasarkan pada frekuensi jawaban yang diberikan. Data hasil oleh data disajikan dalam bentuk diagram dan deskripsi penjelasan mengenai diagram tersebut.

\section{HASIL DAN PEMBAHASAN}

\section{Hasil Survei Aksesibilitas Sosial}

\section{Lingkungan Sosial Positif}

Lingkungan yang positif dilihat dari indikator: sikap keluarga, teman, dan tetangga; interaksi keluarga, tetangga dan teman, serta pemahaman terhadap difabel. Berdasarkan penilaian dari penyandang disabilitas yang menjadi responden, sikap keluarga, tetangga, teman sekolah/kerja terhadap penyandang disabilitas mayoritas baik. Tetapi prosentase sikap acuh tak acuh juga tinggi yaitu di atas 40\%. Mayoritas penyandang disabilitas tidak ada kendala komunikasi dengan keluarga, teman dan tetangga. Keluarga, tetangga dan teman memahami cara berinteraksi dengan penyandang disabilitas, hanya $12 \%$ yang tidak memahami. Mayoritas penyandang disabilitas, yaitu lebih dari $75 \%$ tidak pernah mengalami diskriminasi baik di lingkungan keluarga, sekolah, lingkungan kerja maupun di lingkungan umum. Hasil survei dapat dilihat pada Gambar 1.

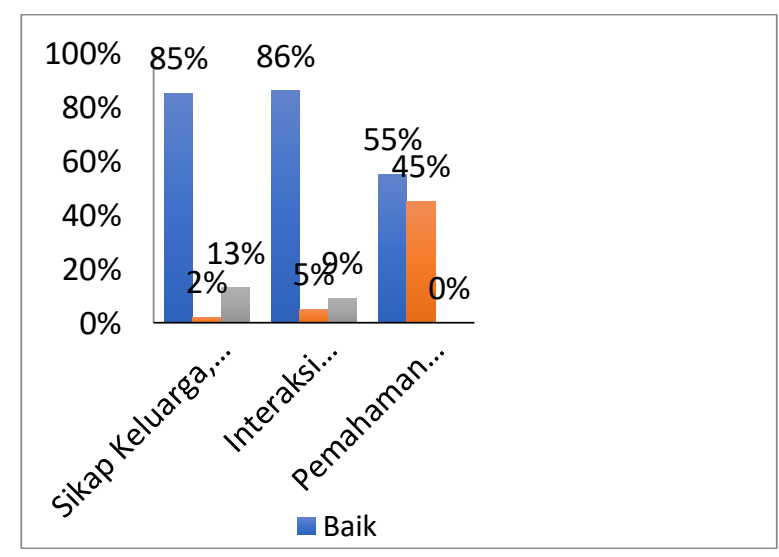

Gambar 1. Hasil survei lingkungan sosial yang positif 
JPPM (Jurnal Pendidikan dan Pemberdayaan Masyarakat), 8 (1), 2021 - 9

Astri Hanjarwati, Jamil Suprihatiningrum, Siti Aminah

Sumber: Hasil olah data peneliti, 2018.

Hasil survei tersebut menggambarkan bahwa masyarakat Desa Trimurti sudah memahami bagaimana harus bersikap dan berinteraksi terhadap penyandang disabilitas. Meskipun yang menjadi dasar sikap tersebut adalah rasa iba dan belum didasari atas pengetahuan mengenai penyandang disabilitas. Fakta ini menjadi modal yang besar untuk menciptakan lingkungan yang inklusif.

\section{Keterjangkauan}

Keterjangkauan ini bertujuan untuk melihat apakah penyandang disabilitas dapat mengakses keuangan/modal, apakah pemerintah dan swasta memberikan investasi/ modal bagi mereka, dan juga apakah tersedia lowongan kerja bagi penyandang disabilitas. Berdasarkan survei mayoritas penyandang disabilitas tidak dapat mengakses/tidak dipercaya oleh Bank maupun pribadi (keluarga/teman/tetangga) untuk meminjam uang. Pemerintah desa tidak memberikan pelayanan bebas biaya sekolah untuk siswa penyandang disabilitas. Hanya 4,1\% penyandang disabilitas bekerja di Pemerintah Desa, sebagai PNS dan 10,2\% difabel bekerja di swasta. Pemerintah Desa, Pemerintah pusat dan Pihak swasta tidak ada yang memberikan modal kepada difabel. Persentase hasil survei dapat dilihat pada Gambar 2.

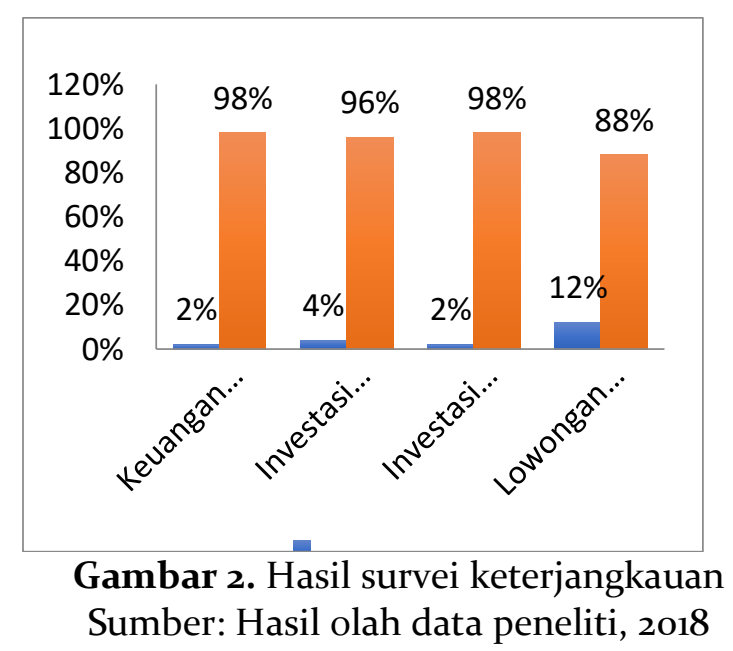

Hasil survei tersebut memberikan gambaran bahwa penyandang disabilitas mempunyai aksesibilitas ekonomi yang sangat minimal atau bahkan tidak mempunyai kesempatan. Hal ini disebabkan oleh: (1) Lembaga keuangan (bank, koperasi) dan tetangga tidak memberikan kepercayaan kepada mereka untuk meminjami uang; (2) Minimnya lowongan kerja baik swasta/ pemerintah yang tersedia bagi penyandang disabilitas; (3) Pihak Pemerintah dan swasta tidak memberikan investasi/modal bagi mereka.

\section{Ketersediaan}

Ketersediaan dilihat dari indikator ketersediaan sarana dan prasarana pendidikan, kesehatan dan layanan serta infomasi di desa bagi peyandang disabilitas. Berdasarkan survei di Desa Trimurti tersedia sekolah yaitu 1 SLB, tetapi hanya 51\% difabel yang dapat menjangkau sekolah tersebut. Layanan kesehatan yang tersedia dan dapat diakses yaitu puskesmas Srandakan. Mayoritas. peyandang disabilitas menyebutkan bahwa layanan desa dapat diakses oleh mereka dan petugasnya ramah dengan mereka.

Hasil survei menunjukkan bahwa ketersediaan sarana prasarana dapat diakses oleh penyandang disabilitas meskipun belum semuanya dapat mengakses. Sarana terbaik yang dapat diakses adalah kesehatan dan layanan informasi desa. Adapun untuk sarana 
JPPM (Jurnal Pendidikan dan Pemberdayaan Masyarakat), 8 (1), 2021 - 10

Astri Hanjarwati, Jamil Suprihatiningrum, Siti Aminah

pendidikan, belum semua penyandang disabilitas dapat mengakses sarana tersebut. Persentase hasil survei dapat dilihat dari Gambar 3.

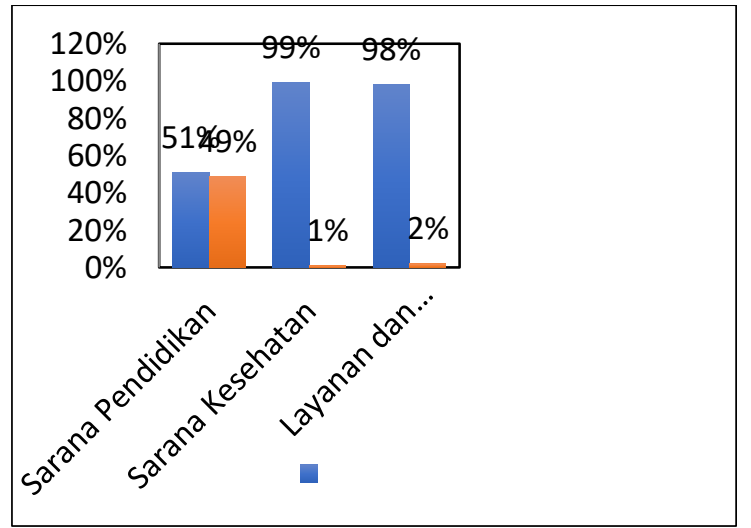

Gambar 3. Hasil survei ketersediaan

Sumber: Hasil olah data peneliti, 2018

\section{Kualitas}

\section{a. Pengarusutamaan}

Indikator pengarusutamaan untuk melihat keterlibatan penyandang disabilitas dalam organisasi. Berdasarkan hasil survei, mayoritas difabel tidak terlibat aktif dalam organisasi penyandang disabilitas dan organisasi yang bersifat umum. Mayoritas difabel juga tidak terlibat dalam kegiatan-kegiatan organisasi penyandang disabilitas dan organisasi umum, sehingga mereka tidak mengetahui dinamika organisasi, kemanfaatan dari kegiatan maupun rekomendasi apa yang harus diberikan kepada stakeholder dari kegiatan tersebut.

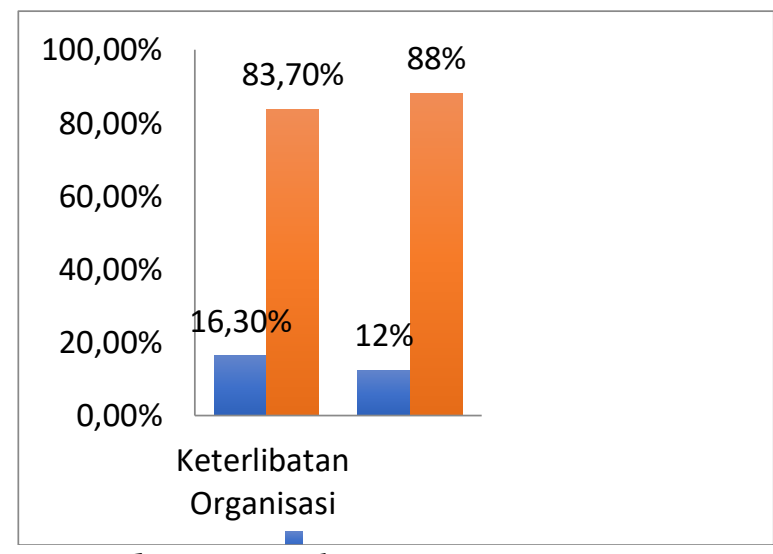

Gambar 4. Hasil survei pengarusutamaan

Sumber: Hasil olah data peneliti, 2018

\section{b. Peran dalam Kegiatan}

Peran dalam kegiatan bertujuan seberapa jauh penyandang disabilitas mempunyai peran baik di level terendah sampai pada level tertinggi. Peran yang dimaksud dikategorikan menjadi narasumber, peserta, panitia dan tidak hadir dalam kegiatan. Berdasarkan pada survei, semua penyandang disabilitas hanya menjadi peserta dalam kegiatan sosialisasi utamanya yang diselenggarakan oleh RT, RW, dukuh dan desa/kelurahan. Fakta ini menunjukkan bahwa partisipasi penyandang disabilitas di Desa Trimurti masih sangat rendah dan keterlibtannya sebagai penerima program atau materi belum sebagai inisiator dari suatu program. 
JPPM (Jurnal Pendidikan dan Pemberdayaan Masyarakat), 8 (1), 2021 - 11

Astri Hanjarwati, Jamil Suprihatiningrum, Siti Aminah

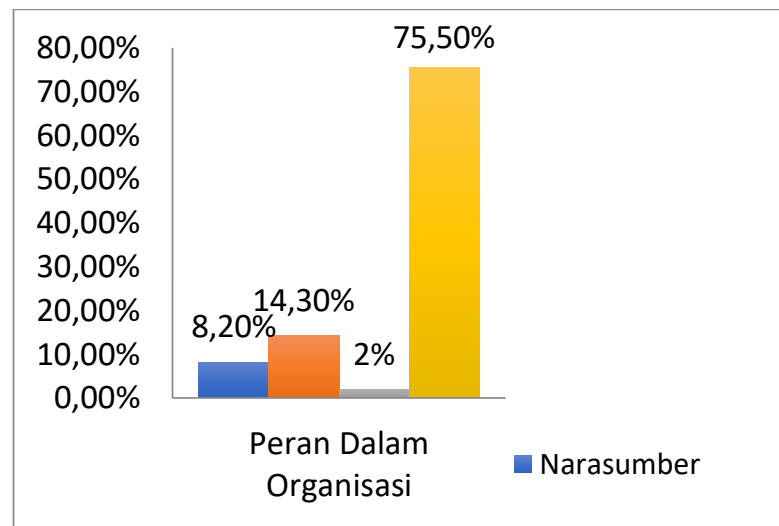

Gambar 5. Hasil survei peran dalam kegiatan

Sumber: Hasil olah data peneliti, 2018

\section{c. Lintas sektor (Menyelenggarakan kegiatan dengan berbagai pihak)}

Lintas sektor yang dimaksud dalam penelitian ini adalah, bagaimana penyandang disabilitas bekerja sama dengan pihal-pihak lain atau tidak. Berdasarkan hasil survei, hanya $12,2 \%$ penyandang disabilitas yang melakukan kerja sama dengan berbagai stakeholder, sedangkan 40,8\% menjawab tidak dan 46,9\% menjawab tidak tahu. Kondisi ini menunjukkan minimnya kerjasama yang dilakukan oleh penyandang disabilitas untuk meningkatkan kapasitasnya maupun kemampuannya. Lebih jelasnya dapat dilihat pada Gambar 6.

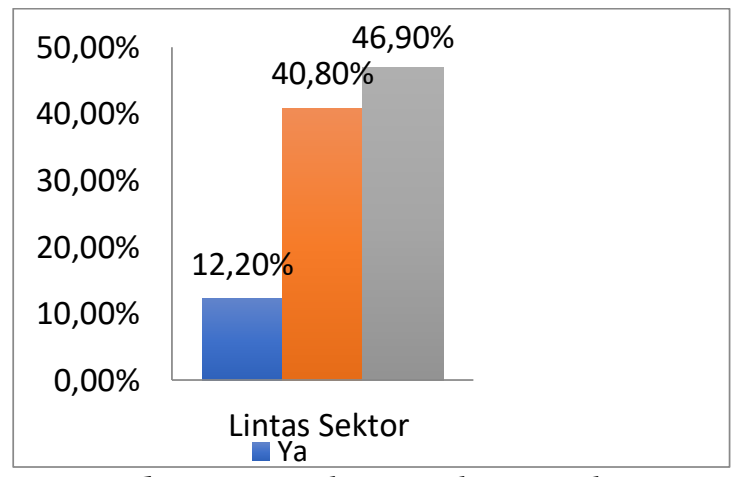

Gambar 6. Hasil survei lintas sektor

Sumber: Hasil olah data peneliti, 2018

\section{d. Konsisten}

Konsistensi dilihat dari dua hal, yaitu: (1)Penyandang disabilitas membawa isu disabilitas apabila bertemu dengan orang lain, (2)Penyandang disabilitas meyakinkan stakeholder, dan masyarakat bahwa mereka mampu berkarya. Hasil survei menunjukkan bahwa mayoritas penyandang disabilitas tidak tahu dan tidak pernah membawa isu disabilitas apabila bertemu dengan orang lain dan tidak pernah meyakinkan stakeholder dan masyarakat/ orang lain bahwa penyandang disabilitas mampu berkarya. Persentase hasil survei dapat dilihat pada Gambar 7 . 
JPPM (Jurnal Pendidikan dan Pemberdayaan Masyarakat), 8 (1), 2021 - 12

Astri Hanjarwati, Jamil Suprihatiningrum, Siti Aminah

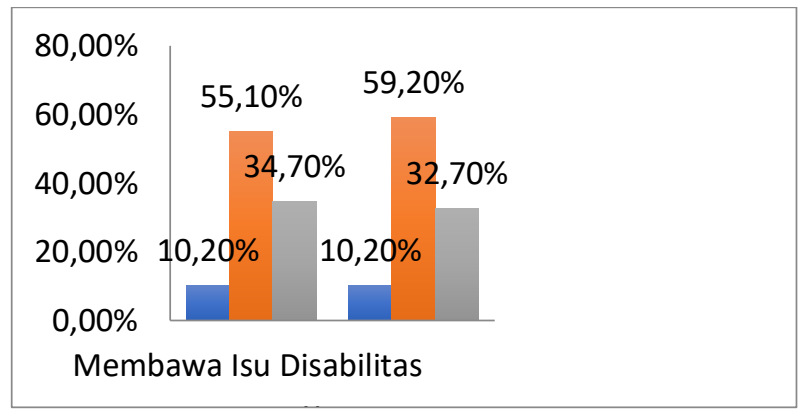

Gambar 7. Hasil survei konsisten

Sumber: Hasil olah data peneliti, 2018

\section{e. Kolaboratif}

Kolaboratif digunakan untuk melihat apakah penyandang disabilitas memiliki kerjasama dengan orang lain atau lembaga lain yang mengusung isu-isu disabiltas. Berdasarkan hasil survei, mayoritas penyandang disabilitas tidak pernah bekerjasama atau memiliki kerja sama dengan orang atau lembaga yang mengusung isu-isu disabilitas. Persentase hasil survei dapat dilihat pada Gambar 8.

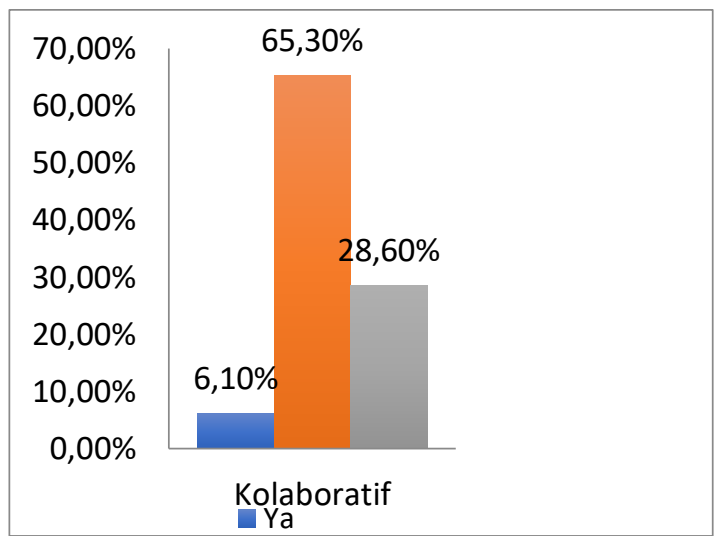

Gambar 8. Hasil survei kolaboratif

Sumber: Hasil olah data peneliti, 2018

\section{Partisipasi Politik}

\section{a. Proses Politik}

1) Partisipasi rapat

Berdasarkan hasil survei partisipasi Penyandang disabilitas dalam menghadiri rapat terbagi dalam beberapa tingkatan yaitu 63,3\% difabel menghadiri rapat RT/RW/dukuh, 18,3\% difabel menghadiri musrenbang tingkat desa; 12,3\% tingkat kecamatan dan 6,1\% tingkat kabupaten. Partisipasi terbesar penyandang disabilitas dalam rapat tingkat RT/RW/dusun. Hal ini disebabkan oleh keterjangkauan lokasi dan juga pelibatan dari stakeholder terhadap penyandang disabilitas. Untuk lebih jelasnya dapat dilihat pada Gambar 9. 
JPPM (Jurnal Pendidikan dan Pemberdayaan Masyarakat), 8 (1), 2021 - 13

Astri Hanjarwati, Jamil Suprihatiningrum, Siti Aminah

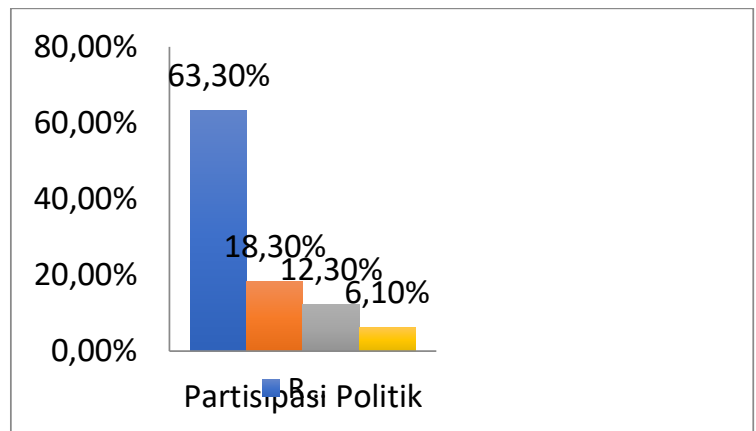

Gambar 9. Hasil survei partisipasi politik

Sumber: Hasil olah data peneliti, 2018

2) Pemilihan anggota musrenbang

Proses pemilihan anggota musrenbang tidak ada sosialisasi mengenai mekanisme tahapannya terhadap penyandang disabilitas. Hal ini menyebabkan mayoritas difabel tidak tahu bahwa ada rapat pemilihan wakil warga untuk menghadiri musrenbang. Untuk lebih jelasnya hasil survei dapat dilihat pada Gambar 10.

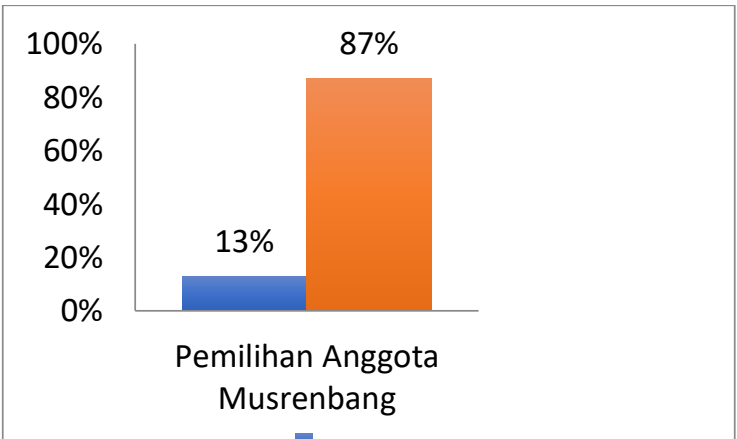

Gambar 10. Hasil survei pemilihan anggota musrenbang Sumber: Hasil olah data peneliti, 2018

3) Menyampaikan usulan setiap rapat

Mayoritas penyandang disabilitas yaitu 79,6\% menyampaikan usulan setiap rapat. Fakta ini menunjukkan bahwa kesadaran penyandang disabilitas untuk menyampaikan usulan sudah cukup bagus. Prosentase hasil survei dapat dilihat pada Gambar 11.

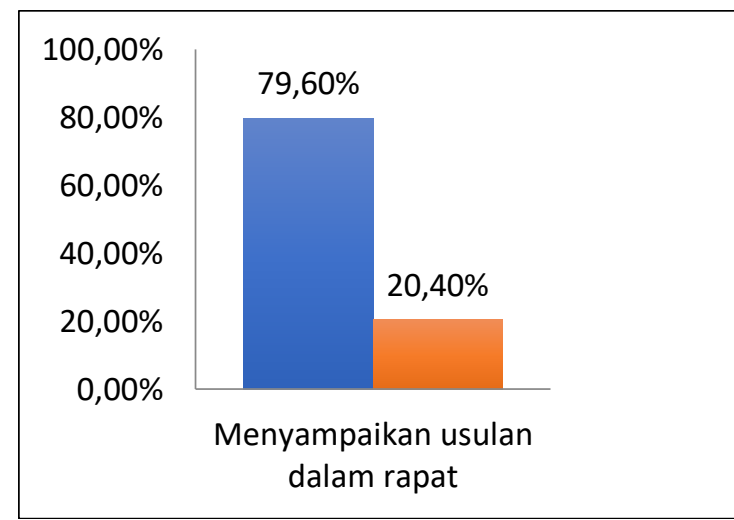

Gambar 11. Hasil survei menyampaikan usulan dalam rapat Sumber: Hasil olah data peneliti, 2018 
JPPM (Jurnal Pendidikan dan Pemberdayaan Masyarakat), 8 (1), 2021 - 14

Astri Hanjarwati, Jamil Suprihatiningrum, Siti Aminah

4) Pelibatan Peyandang Disabilitas dalam Rapat

Berdasarkan pada survei, mayoritas penyandang disabilitas dilibatkan dalam rapat tingkat $\mathrm{RT} / \mathrm{RW}$ dan dukuh untuk menjaring aspirasi pembangunan desa. Persentase hasil survei dapat dilihat pada Gambar 12.

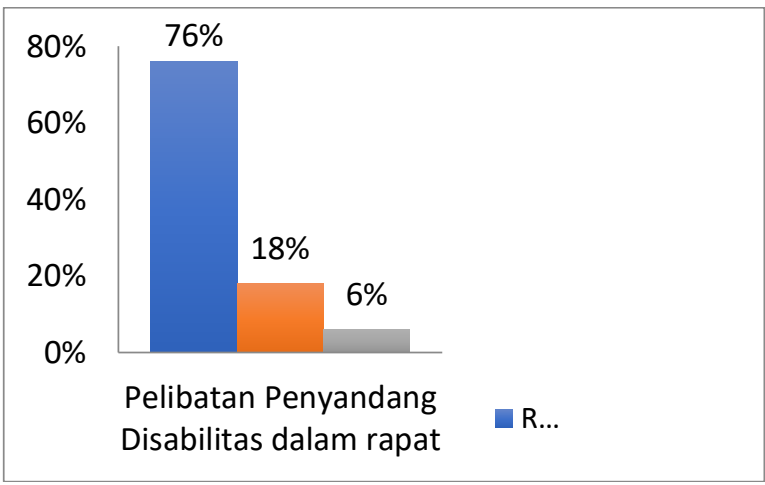

Gambar 12. Hasil survei pelibatan penyandang disabilitas dalam rapat

Sumber: Hasil olah data peneliti, 2018

5) Musrenbang menerima usulan Penyandang disabilitas

Berdasarkan pada hasil survei, mayoritas penyandang disabilitas menyatakan bahwa Musrenbang Desa sudah menerima usulan/masukan dan keluhan warga miskin dan kaum perempuan. Untuk lebih jelasnya dapat dilihat pada Gambar 13.

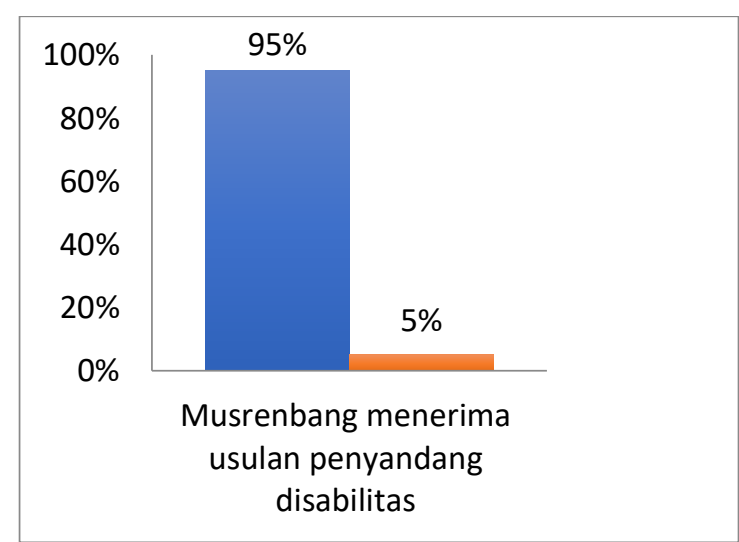

Gambar 13. Hasil survei musrenbang menerima usulan penyandang disabilitas

Sumber: Hasil olah data peneliti, 2018

\section{b. Kebijakan Politik}

Desa Mengakomodasi Hak-Hak Penyandang Disabilitas. Berdasarkan hasil survei $71,4 \%$ penyandang disabilitas menyatakan tidak tahu apakah desa sudah mengakomodasi hak-hak dan kepentingan penyandang disabilitas dalam setiap pengambilan keputusan. Persentase hasil survei dapat dilihat pada Gambar 14. 
JPPM (Jurnal Pendidikan dan Pemberdayaan Masyarakat), 8 (1), 2021 - 15

Astri Hanjarwati, Jamil Suprihatiningrum, Siti Aminah

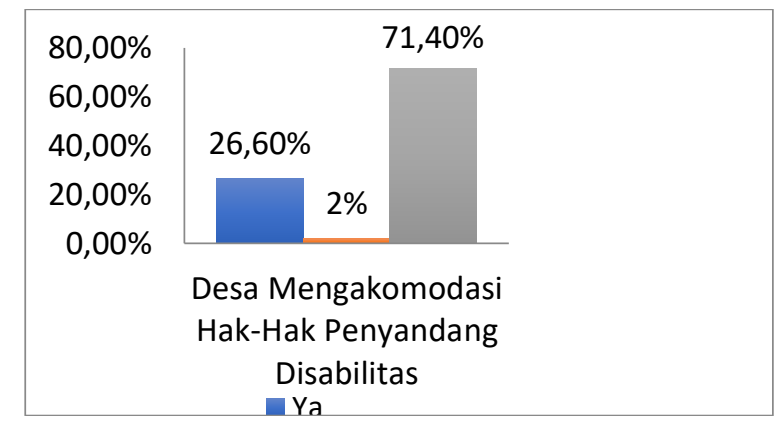

Gambar 14. Hasil survei desa mengakomodasi hak-hak penyandang disabilitas

Sumber: Hasil olah data peneliti, 2018

1) Penyandang Disabilitas sebagai sasaran program

Berdasarkan hasil survei, mayoritas penyandang disabilitas tidak mengetahui apakah peraturan desa telah menempatkan mereka sebagai sasaran program kegiatan dan sebagai subjek pembangunan. Persentase hasil survei dapat dilihat pada Gambar 15.

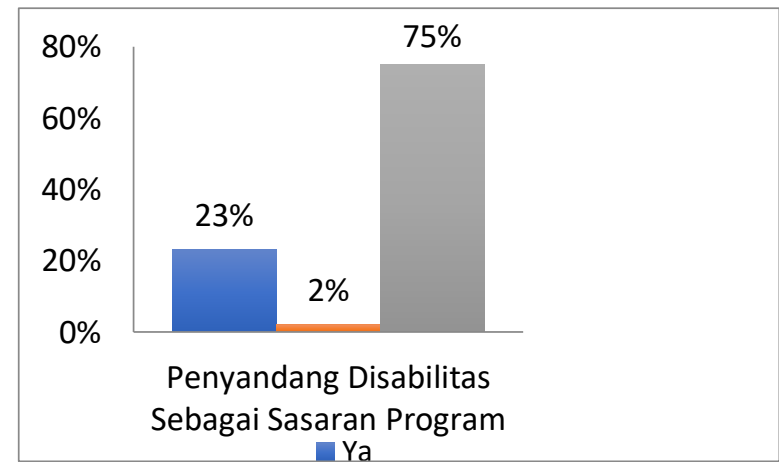

Gambar 15. Hasil survei penyandang disabilitas sebagai sasaran program

Sumber: Hasil olah data peneliti, 2018

\section{SIMPULAN}

Aksesibilitas sosial dilihat dari aspek sikap lingkungan terhadap penyandang disabilitas, ketersediaan, dan proses politik. Sikap keluarga, tetangga, dan teman penyandang disabilitas cukup baik, hanya beberapa persen yang bersikap acuh tak acuh. Variabel kedua yang cukup baik adalah ketersediaan. Jangkauan penyandang disabilitas terhadap sarana pendidikan (SLB), layanan kesehatan dan informasi cukup baik, diatas 50\%. Variabel ketiga yaitu proses politik, dimana mayoritas penyandang disabilitas hadir dalam rapat di tingkat RT/RW dan dusun serta menyampaikan usulan dalam rapat.

Kondisi yang belum aksesibel bagi penyandang disabilitas adalah keuangan, pengetahuan, investasi pemerintah dan swasta, pengarusutamaan, konsistensi dan kolaboratif. Keluarga, teman, tetangga dan lembaga keuangan tidak percaya meminjamkan uang kepada penyandang disabilitas. Hal ini mengakibatkan penyandang disabilitas kesulitan dalam mendapatkan modal untuk meningkatkan kesejahteraannya. Pihak pemerintah maupun swasta juga tidak pernah melakukan investasi untuk memberikan modal kepada penyandang disabilitas. Lowongan pekerjaan yang tersedia bagi penyandang disabilitas sangat terbatas, hanya sekitar $5 \%$ penyandang disabilitas yang bekerja di sektor swasta dan pemerintah. Penyandang disabilitas mayoritas tidak terlibat dalam kerjasama dengan berbagai stakeholder dan mereka rata-rata tidak mempunyai inisiatif untuk melakukan advokasi atas isu-isu disabilitas. 
Bangunan fisik di Desa Trimurti, Kecamatan Srandakan, Kabupaten Bantul mayoritas belum aksesibel bagi pengguna kursi roda dan juga tongkat putih. Berdasarkan hasil survei, bangunan fisik yang sudah aksesibel adalah Sekolah Luar Biasa (SLB) dan Puskesmas. Dua gedung tersebut yang tersedia hanya ramp sedangkan guiding block belum tersedia. Sarana publik lainnya, yang berupa kantor desa, kantor kecamatan, KUA, polsek, sekolah umum dan tempat ibadah tidak aksesibel. Ramp belum tersedia sehingga sulit diakses pengguna kursi roda.

\section{DAFTAR PUSTAKA}

AUSAID. (2010). Accessibility Design Guide: Universal Design Principle for Australia's Aid Program. Canberra: Clarity Communication.

Australian Government Department of Health and Ageing. (2009). Design Principle - Social Inclusion. Australia: Healthy Spaces \& Places, retrieved from www.healthyplaces.org.au

Australian Government, 2008, 'Social Inclusion Principles for Social Inclusion in Australia' http://www.socialinclusion.gov.au/

Barnes, C., \& Mercer, G. (2004). Theorising and Researching Disability from a Social Model Perspective. Chapter 1 (In 'Implementing the Social Model of Disability: Theory and Research' edited by Colin Barnes and Geof Mercer (2004). Leeds: The Disability Press, pp. $1-17)$.

CABE. (2006). The principles of inclusive design. (They include you). UK: Commission for Architecture and the Built Environment.

CABE. (2008). Inclusion by design: Equality, diversity, and the built environment. UK: Commission for Architecture and the Built Environment.

Center for Excellent in Universal Design. (2017). Building for Everyone: Universal Design Approach. Dublin: National Disability Authority.

Ciqal. (2016). Barrier Assessment, studi di Kabupaten Gunung Kidul dan Kupang. Yogyakarta: Ciqal, Laporan tidak diterbitkan.

Clarkson, J., Coleman, R., Keates, S., \& Lebbon, C. 2003. Inclusive Design: Design for the whole population. London: Springer, DOI: 10.1007/978-1-4471-00o1-o

Colantonio, A. \& Dixon, T. (2009). Measuring Socially Sustainable Urban Regeneration in Europe. Oxford Brookes University: Oxford Institute for Sustainable Development.

Data Dinas Sosial Kabupaten Bantul tahun 2015

DFAT. (2009). Accessibility Design Guide: Universal design principles for Australia's aid program 2009 - 2014. Canberra: AUSAid

Donahue, S. \& Gheerawo, R. (2007). Social concerns - new challenges for inclusive design. Conference Paper.

Edmonds, L.J. (2005). Disabled People and Development. POVERTY AND SOCIAL DEVELOPMENT PAPERS No. 12/ June 2005. Poverty Reduction and Social Development Division Regional and Sustainable Development Department Asian Development Bank.

Elina, K. \& Ann, H. (2012). How to Design for Others if We Only Have Our Own Experience to Rely on?. ANTWERP: Theory by Design Conference.

Ferguson, P.M. \& Nusbaum, E. (2012). Disability Studies: What Is It and What Difference Does It Make?. Research \& Practice for People with Severe Disabilities, Vol. 37, No. 2, 70-8o.

Ferrie, D., (2008) 'Social Inclusion and Place Based Disadvantage', proceedings from Social Inclusion and Place Based Disadvantage Workshop. Brotherhood of St Laurence.

Hart District Council. (2009). Yateley Village Design Framework. Hampshire: Hart District Council.

Hayes, A., Gray, M. and Edwards, B. (2008), 'Social Inclusion; Origins, Concepts and Key Themes', Australian Institute of Family Studies prepared for the Social Inclusion Unit, Department of the Prime Minister and Cabinet. 
Heinicke-Motsch, K. \& Sygall, S. (2003). Building an Inclusive Development Community: A Manual on Including People with Disabilities in International Development Programs. USA: Mobility International USA (MIUSA).

Knight, G. \& Bichard, J. (2011). Publicly Accessible Toilets: An Inclusive Design Guide. London: Royal College of Art Helen Hamlyn Centre for Design

Maftuhin, A., Aminah, S., Mitra, B. (2016). Renaksi Kota Inklusif Yogyakarta. Laporan (tidak dipublikasikan). Kerjasama antara Badan Perencanaan dan Pembangunan Daerah Kota Yogyakarta dan Lembaga Penelitian dan pengabdian kepada Masyarakat (LPPM) UIN Sunan Kalijaga Yogyakarta.

Malloy, R.P. (2015). Land use and disability: planning and zoning for accessible community. USA: Cambridge University Press.

Palich, N. \& Edmonds, A. (2013). Social sustainability: creating places and participatory processes that perform well for people. Australia: Environment Design Guide

Rapley, C.E. (2013). Accessibility and Development: environmental accessibility and its implications for inclusive, sustainable and equitable development for all. The Department of Economic and Social Affairs (DESA) of the United Nations.

Ro'fah, Hanjarwati, A., Suprihatiningrum, J. (2016). Assessment Hambatan Pelibatan dan Partisipasi Penuh Kelompok Marginal dalam Perencanaan dan Proses Pembangunan Daerah - Barrier to Access. Laporan penelitian, tidak diterbitkan.

Salisbury District Council Core Strategy Consultation. (2007). Access for all: Creating an inclusive environment. Salisbury District Council.

Smeltzer, S.C. (2007). Improving the health and wellness of persons with disabilities: A call to action too important for nursing to ignore. Nurs Outlook, 55: 189-195.

The Center for Universal Design (1997). The Principles of Universal Design, Version 2.o. Raleigh, NC: North Carolina State University.

Tim penyusun CBR UIN Sunan Ampel. 2016.

UU No 6 tahun 2014 tentang Desa

Waldschmidt, A. (2017). Disability Goes Cultural: The Cultural Model of Disability as an Analytical Tool, Waldschmidt, A., Berressem, H., Ingwersen, M. (Eds). Germany: the UzK Forum Initiative, University of Cologne.

West, S., Badham, M. (2008). 'A Strategic Framework for Creating Liveable Communities' prepared for the Growth Areas Authority Victoria with assistance from the University of Melbourne, Griffith University and the McCaughey Centre.

Western Australian Planning Commission, (2007). Liveable Neighbourhoods. Western Australian Planning Commission, Perth.

Wood, L., Shannon, T., Bulsara, M., Pikora, T., McCormack, G. and Giles-Corti, B. (2008), 'The Anatomy of the Safe and Social Suburb: an exploratory study of the built environment, social capital and residents' perceptions of safety', Health \& Place, 14(1), pp15-31 in Bicycle Federation of Australia 'Cycling Fact Sheet'. http://www.ncbi.nlm.nih.gov/pubmed/17576088

Woodcraft S, T Hackett \& L Caistor-Arendar. (2011). Design for Social Sustainability: A framework for creating thriving new communities. London: The Young Foundation. 